\title{
Latidos no escritório
}

cão faz parte da convivência humana há séculos. No oci-
dente, em particular, suas representações sociais fizeram
dele alvo de estima e carinho, com um papel importante em diversas atividades. Mais recentemente, a função social do cão está sendo ampliada. Nos EUA, ele está começando a fazer parte do quadro das empresas, sendo levado por seus donos, ao ambiente de trabal ho. 0 artigo analisa as bases desse fenômeno e suas implicações em termos de gestão de pessoas na atualidade.

por Carlos Osmar Bertero FGV-EAESP

0 ocidente convencionou a representação de que o cão é o melhor amigo do homem. N ormalmente, as características que descrevem o vínculo de homens e cães o fazem na perspectiva da amizade, incluindo valores como lealdade, companheirismo e uma obstinada atitude de apego e reverência ao dono por parte do animal. Sendo ou não um lugar-comum, fato é que, quando comparado a outros primatas, o comportamento do cão parece mesmo confirmar sua natureza afetu osa e companheira, al go às vezes distante da compreensão mesmo dos humanos.

De um ponto de vista sociológico, a relação entre homens e cães foi sendo construída ao longo do tempo 
de modo que os segundos atendem a propósitos específicos dos primeiros. Além da amizade doméstica, os cães serviram - e servem - como companheiros de guarda em acampamentos; como auxiliares no pastoreio de gado domesticado e nas caças, e como companhia dos soldados nos campos de batalha.

Porém, na atualidade, um novo uso vem sendo feito dos cães. Em alguns países, como nos EUA, eles foram levados para o ambiente de trabal ho, onde fazem parte da rotina diária de seus donos e, em alguns casos, tornam-se membros simbólicos da cultura organizacional. 0 propósito deste artigo é analisar esse fenômeno corporativo recente. Nosso ponto é discutir os antecedentes que tornaram possível essa invasão de fronteiras e instigar o leitor sobre se o fenômeno refere-se a um novo modismo gerencial ou se, pelo contrário, tem algo a nos dizer sobre satisfação e presas pós-industriais. produtividade nas novas condições de trabalho das em-

países mais "caninos" do que outros. A Inglaterra foi o berço de grande número de raças nos últimos quatro séculos. $\mathrm{Na}$ Europa ainda merecem destaque a Alemanha, a França e a Itália como países que tiveram e ainda possuem grande importância para a cinofilia.

As representações dadas aos cães no ocidente dependem de uma compreensão mais ampla de al guns fenômenos sociais, dos quais as mudanças no sentido e na composição das famílias éo mais emblemático. Defato, a família, que de extensa passou a nuclear, é hoje formada por um pequeno número de pessoas que coabitam o mesmo espaço físico com laços são cada vez mais frágeis e instáveis.

A conseqüência dessa alteração na estrutura da família é o crescentenúmero de pessoas vivendo sós ou então sem vínculos de longa duração entre si. Somado a isso, há também a solidão resultante da mobilidade geográfica, que se acelerou nos últimos anos e rompeu os vínculos das pessoas baseados em local de nascimento e tradição. Vivendo em grandes centros urbanos, elas têm de lidar com o paradoxo de estar no meio de muitas outras, mas, ao mesmo tempo, não ter com elas qualquer vínculo social significativo.

Em meio a todas essas transformações, destaca-se a função social do cão, com quem as pessoas estabelecem vínculos afetivos fortes, muitas vezes em concorrência com as demais formas de vínculos tipicamente humanos. Na prática, o cão segue o humano - se este muda do campo para a cidade, ele o acompanha; se a estrutura da família se altera, o cão passa a conviver com

Cães e humanos. Em quase todas as culturas, o cão é um animal domesticado eintocado. Apesar de sua enorme fertilidade e facilidade reprodutiva, não éconsiderado animal de abate, salvo poucas exceções. Em al gumas culturas ele é considerado um animal "sujo" ou "impuro", mas, no ocidente, é em geral visto como amistoso, amigo da espécie humana e merecedor de afeição e respeito.

$N$ ão seria inverdade afirmar que a cinofilia, enquanto amor, amizade, respeito e dedicação ao cão, tem raízes mais profundas em alguns países e que, mesmo atualmente, há todos. Em resposta à nuclearização da família e à saída dos filhos de casa mesmo sem contraírem matrimônio, 0 cão se faz presente em todos os momentos e em todas as casas e apartamentos onde as pessoas resolvam se instalar. 0 histórico companheiro parece indiferente a essas mudanças que os humanos vêm fazendo em suas vidas e formas de convivência.

Cães e empresas. Os Estados Unidos são hoje, certamente, o país em que o cão está mais intimamente 
ligado aos humanos, chegando mesmo a estimular aspectos radicais de relacionamento. As peculiaridades desse país e a sua origem cultural proveniente da Inglaterra ajudam a explicar a posição do cão em sua sociedade e, conseqüentemente, a maneira como se relaciona com os humanos. Adicionalmente, é provável que o individualismo norte-americano também exerça força como matriz cultural em que se fundamenta o vínculo homem-cão naquele país.

Assim, não é exagero afirmar que, nos EUA, o cão é um substituto dos filhos, dos pais, dos irmãos e irmãs e muitas vezes éo único amigo. Dorme em casa, brinca com as crianças e acompanha os adultos. Q uando os filhos vão para a universidade, levam consigo um cão; nos dormitórios e em praticamente todas as áreas de uma universidade norte-americana os cães estão presentes, de modo que não é incomum que em muitas instituições eles assistam às aulas com seus donos. Acompanham os adultos até mesmo na prática de esportes. Há cães caçadores e há os que vão também a parques públicos desfrutar o lazer com seus proprietários.

Mais recentemente, os norte-americanos sofisticaram o vínculo com seus cães, passando a levá-los ao trabalho. M as o que os cães fazem nas empresas? Tal movimento não constitui uma inversão na imagem tradicional da empresa como ambiente em que deve imperar a racionalidade, 0 controle e a "seriedade"?

Um olhar isento sobre al gumas práticas gerenciais norteamericanas em relação aos cães podem nos dar a resposta. Vemos então que os cães têm por lá uma série de "atribuições". Tomemos alguns exemplos retirados do noticiário da imprensa norte-americana. Para Riley, um cão de 6 anos que trabalha com sua dona, uma secretária, o seu trabalho consiste em ficar deitado durante seis horas diárias aos pés de sua dona enquanto ela digita e atende tel efonemas.

A empresa Phelps Group, uma agência de propaganda local izada na cidade de Santa M ônica, na Califórnia, tem em seu quadro 55 humanos e 8 cães. Suas tarefas são essencialmente estéticas: servem de inspiração aos profissionais humanos para o desenvolvimento de campanhas publicitárias e para a redação de textos. A agência obtevegrandesucesso ao criar um slogan para um cliente, a Pet Company: Petco, where the pets go [ "Petco, o lugar em que até os cães vão"].

Já em uma outra empresa, a Urban Space Development, uma empresa imobiliária, os três cães, Lola, Leo e Max, atuam como "facilitadores". Q uando as tensões entre os clientes se exacerbam, especialmente em função de reclamações sobre os serviços da imobiliária ou durante a negociação de contratos de locação, os três cães abanam os rabos, ol ham meigamente para os tensos humanos e se

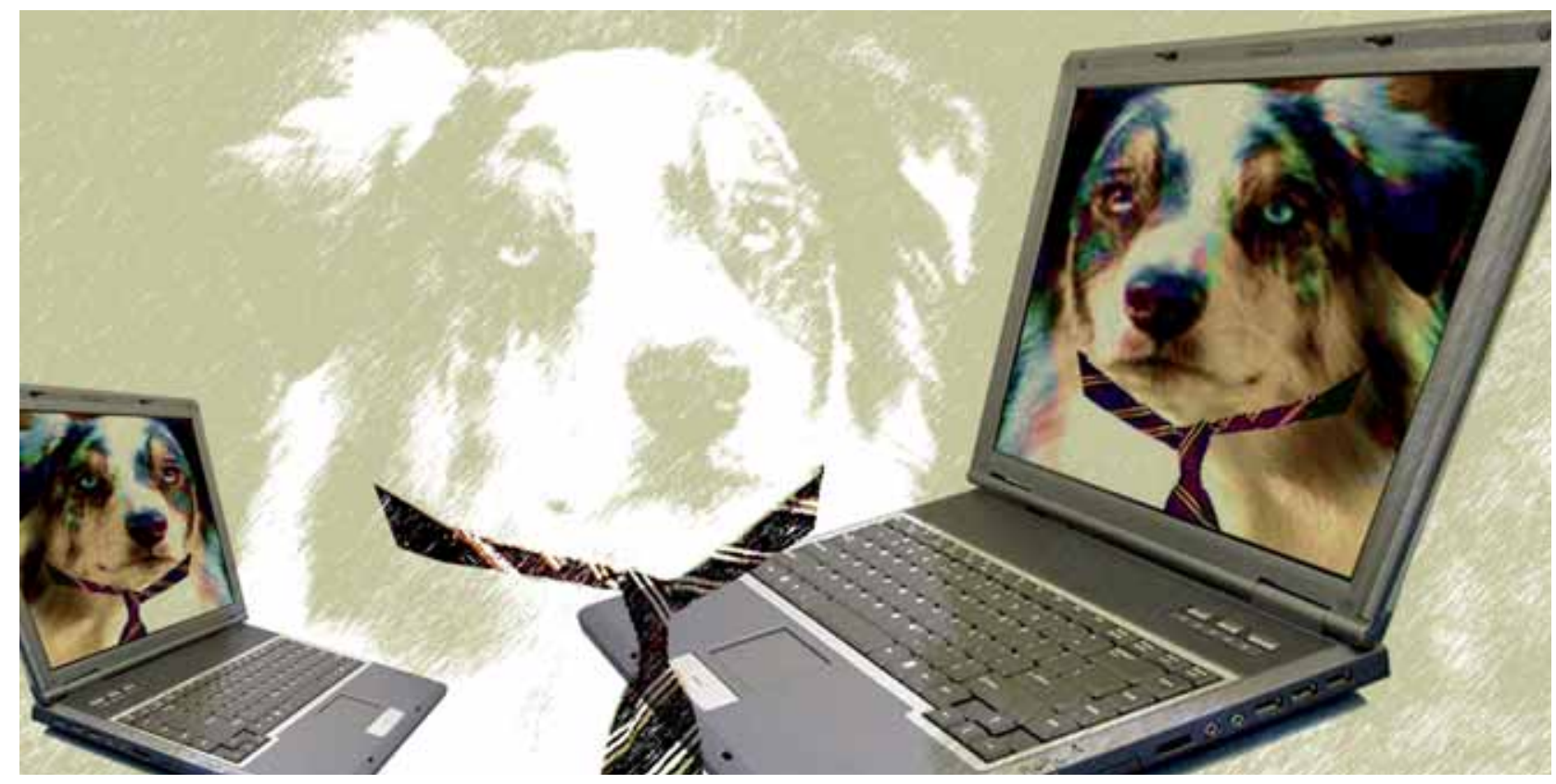


oferecem para receber carinhos. Segundo o presidente da empresa, eles contribuem para iluminar e descontrair 0 ambiente de trabalho.

Mas há cães com "cargos executivos" e com responsabilidades específicas. É o caso de Charlotte, uma cadela terrier que trabalha na Jen Lew Designs, na cidade de Mattituck, em Long Island, e cujo nome aparece em toda a correspondência da empresa como Chefe de Serviços ao Consumidor, recebendo e-mails dos clientes sempre que surge um problema a ser solucionado. A avaliação

\section{Paradoxalmente, à medida que os}

\section{benefícios que empregadores costumavam}

\section{oferecer aos seus empregados estão em}

\section{vertiginoso declínio, a compensação pela} aceitação dos cães parece ser uma inovação

\section{para equilibrar a dura vida corporativa dos trabal hadores norte-americanos.}

da supervisora imediata de Charlotte, a proprietária da empresa, Jenifer Lew, é de que seu desempenho no cargo é excelente, poupando à empresa grandes dores de cabeça, especialmente com clientes mais difíceis e exigentes.

RH e cães. Os fatos referidos nos parágrafos anteriores foram extraídos da coluna de Lisa Belkin, publicada quinzenalmente no prestigiado The N ew York Times. A coluna é voltada para questões sobre "intersecção entre o trabalho e a vida pessoal" das pessoas. No diagnóstico de Belkin, a prática de levar cães ao trabalho, apesar de, por enquanto, não ser al go rotineiro nos EUA, tem grandes chances de vir a sê-lo, e em nenhum momento questiona-se a legitimidade da idéia ou se se trata de um modismo passageiro ou de alguma nova excentricidade típica do mundo executivo norte-americano.

Primeiro, porque as empresas fazem questão de dar à aceitação de cães na empresa o caráter de uma concessão e de um benefício. Paradoxalmente, à medida que os demais benefícios que empregadores costumavam oferecer aos seus empregados naquele país, como atraentes fundos de pensão, seguros de saúde, carreiras claramente definidas e aumentos regulares de salários, estão em vertiginoso declínio, a compensação pela aceitação dos cães parece ser uma "inovação" para equilibrar - ou mascarar - a dura vida corporativa dos trabalhadores norte-americanos de colarinho-branco. Existe, porém, alguma evidência que aponte no sentido de benefícios reais na convivência com cães, especificamente no ambiente de trabalho?

A resposta para essa questão não pode ser dada em definitivo. Contudo, aparentemente há mais benefícios do que prejuízos na interação com cães no ambiente de trabalho. É claro que, do ponto de vista prático e, digamos, "logístico", seriam necessárias algumas adaptações e alterações de comportamento, tanto da parte dos caninos como dos humanos. Cães precisam ser treinados para conviver em ambientes sociais; por seu turno, os humanos têm de arranjar o ambiente de modo a acomodá-los da melhor maneira possível para ambos.

A despeito disso, os resultados podem ser positivos: para os humanos, a companhia dos cães parece fator importante que os encoraja a permanecer na empresa. Também não se pode negar que seres humanos parecem melhorar quando interagem com cães. Embora a interface homem-animal ainda seja pouco estudada e conhecida, há evidências de que pessoas que vivem sós têm mais problemas com depressão do que as que vivem com cães. Além disso, existem benefícios que cães promovem aos humanos, como se observa nos diversos serviços de apoio a pacientes em hospitais.

Mesmo assim, não éalgo fácil desenvolver uma cadeia causal que assegure uma relação positiva entre a presença de cães no local de trabal ho ea mel horia do clima organizacional, levando ao melhor relacionamento entre as pessoas e ao aumento de motivação com reflexos positivos sobre a 
produtividade da empresa e a qualidade de seus produtos e serviços. Todas essas relações, embora freqüentemente repetidas na retórica da gestão de pessoas, são de difícil e problemática comprovação.

Neste ponto podemos nos questionar se a prática de levar cães ao escritório não éalgo que apenas faz sentido à luz da realidade norte-americana, tendo em vista o val or que o cão possui naquela cultura. Desse modo, haveria algum sentido em estender essa prática às empresas brasileiras?

Cães e empresas no Brasil. Já foram apontadas as diferenças culturais com relação ao relacionamento entre homens e cães quando se afirmou que há países "mais caninos" que outros. E como éo nosso país? Aparentemente, os cães aqui estão em alta. Indicadores são fornecidos pela indústria de alimentos para cães, que registram substanciais aumentos de faturamento, o que indica mais cães e especialmente cães mais bem cuidados e alimentados.

Outro dado é que também aumentou o número de pet shops e de consultórios de veterinários no país. No entanto, é enorme o número de cães abandonados a perambular por ruas e estradas, com suas vidas reduzidas pela falta de alimento, sendo maltratados e mortos por atropelamentos em ruas e estradas.

Esse abandono indica uma sociedade que ainda não convive em termos civilizados com nosso mais antigo amigo. Ademais, no Brasil ainda há uma resistência e sérias reservas à presença do cão na maioria dos locais. Há não muito tempo uma passageira cega com seu cão-guia foi barrada em uma estação do metrô de São Paulo. Depois de al gum tumulto e intervenção da Justiça, a empresa teve de alterar sua prática e aceitar cães-guias. N os Estados U nidos cães-guias viajam até em aviões com seus proprietários cegos e com direto a assento na cabine de passageiros ao lado do dono. Portanto, parece que ainda estamos a al guma distância de termos no país cães latindo nos escritórios.

Mas, nesses dias de mudanças rápidas e especialmente em que as práticas se difundem com grande velocidade, 0 exemplo que nos vem dos Estados Unidos é interessante. A empresa éo local onde passamos a maior parte do tempo

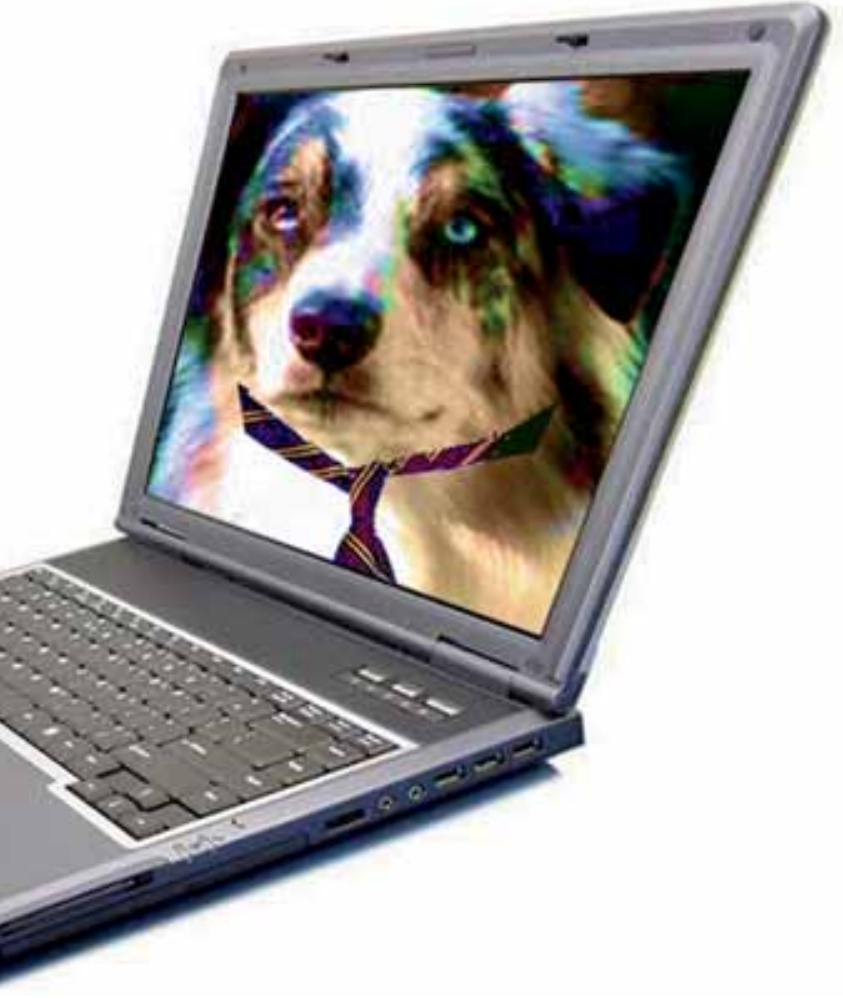

e, de resto, a maior parte de nossas vidas. Se comparadas com o passado pré-industrial, veremos que, na origem, as pessoas viviam e trabalhavam em suas casas, de sorte que a residência e o local de trabalho estavam unificados.

Com a industrialização e a urbanização, os locais de trabalho e moradia foram separados. Conseqüentemente, passa-se hoje mais tempo no trabal ho do que no lar. Não é de estranhar, pelo menos à primeira vista, que os cães, que conosco estavam em casa, também conosco fossem para 0 trabalho. A convivência ao longo dos séculos tem sido mutuamente (para eles e para nós) gratificante e recompensadora. Talvez tenha chegado a hora de testá-los em ambientes industriais e pós-industriais, em organizações intensivas em conhecimento e que usam as mais avançadas tecnologias.

Carlos Osmar Bertero

Doutor em Administração pela Cornell University

Prof. do Departamento de Administração Geral e Recursos Humanos da FGV-EAESP

E-mail: carlos.bertero@fgv.br 